\section{International Materials Research Committee Holds Inaugural Meeting}

Forty-six scientists from 12 countries attended the inaugural meeting of the International Materials Research Committee (IMRC) on November 30, 1989 to ratify statutes and elect its first executive committee. Hosted by the Materials Research Society during its 1989 Fall Meeting in Boston, the IMRC inaugural meeting was the culmination of many months of preparation and organization by materials scientists around the world to foster international cooperation to advance the multidisciplinary nature of materials research.

The establishment of IMRC is viewed as a first step toward developing an international union or federation serving the materials research community.

Attending scientists from Australia; Brazil; Beijing, China; Taiwan, China; France; Federal Republic of Germany; India; Italy; Japan; Mexico; United Kingdom; and the
United States represented the founding "Adhering Bodies" of IMRC and other scientific groups from their nations or regions of the world. *

The International Materials Research Committee was established to (1) facilitate international cooperation among materials research organizations, (2) advance the multidisciplinary nature of materials research internationally, (3) promote information exchange among national or regional societies, (4) promote communication of international materials research activities through appropriate media, and (5) encourage well-established materials research symposia to rotate through available meeting sites of materials research societies. Members of the IMRC are the Adhering Bodies which represent societies or associations of societies whose purpose is to promote interdisciplinary materials re- search. Any number of societies from a nation or region may join together to form an Adhering Body. Membership is conferred by the approval of the General Assembly.

\section{Executive Committee Elected}

The most important item of business accomplished during the inaugural meeting was the election of an executive committee to lead the IMRC. Prof. R.P.H. Chang of Northwestern University was elected chairperson; Prof. Paul Siffert of the Centre de Recherches Nucléaires, vice chairperson; Prof. R.C. Ewing of the University of New Mexico, secretary; and Prof. Shigeyuki Sōmiya of Nishi Tokyo University, treasurer. The executive committee then undertook establishment of a system of subcommittees or commissions to attend to IMRC business.

\section{Adhering Bodies Report Activity}

The founding Adhering Bodies, already having active programs, gave progress reports during the meeting. R.P.H. Chang, 1989 president of the Materials Research

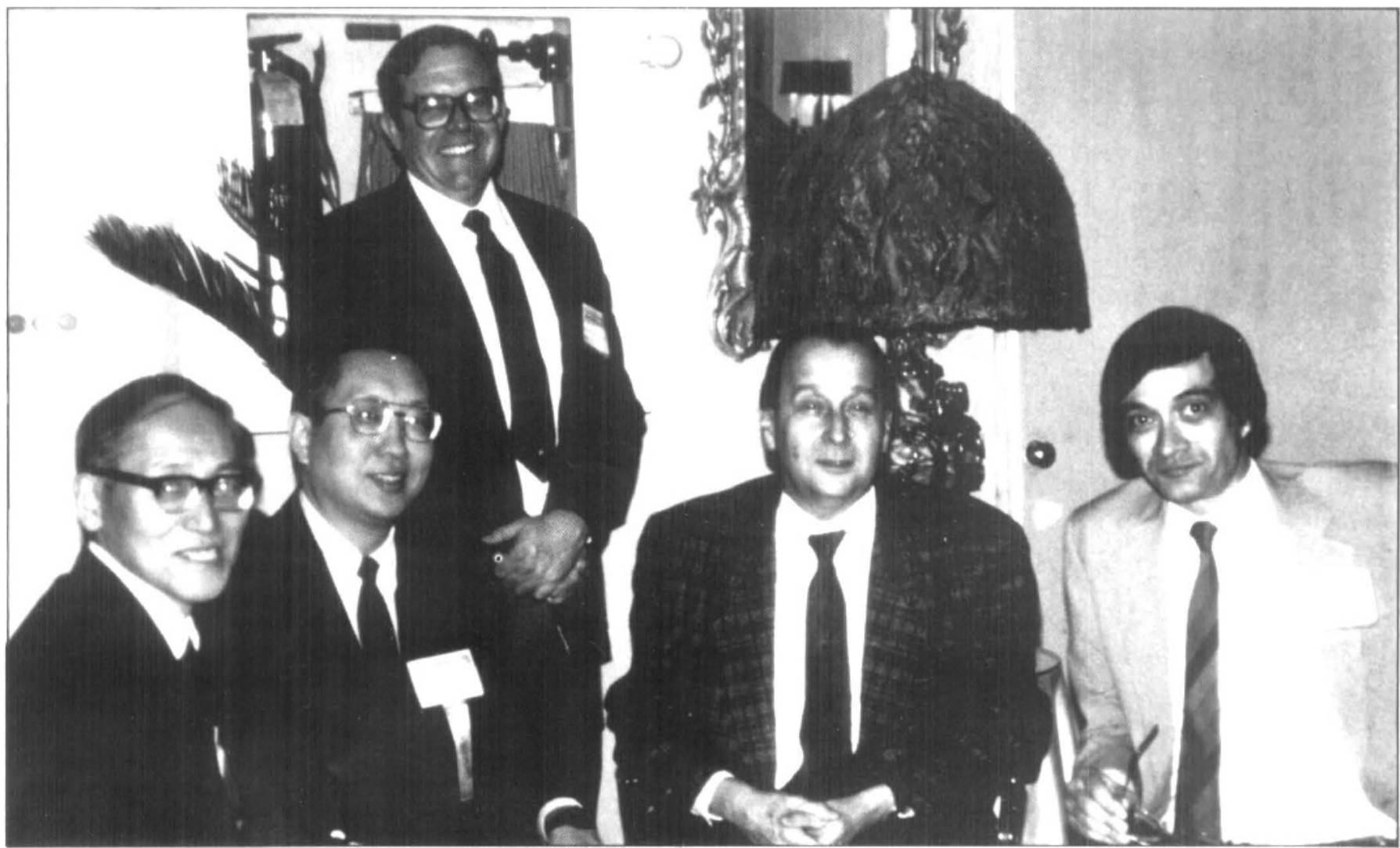

C.W. (Woody) White (standing), chair of the MRS Subcommittee on International Relations, with (left to right): Masao Doyama, president of the Advanced Materials Science and Engineering Society in Japan; R.P.H. Chang, chair, IMRC Executive Committee; Paul Siffert, vice chair, IMRC Executive Committee; and R.C. Ewing, secretary, IMRC Executive Committee. 
Society, noted that MRS membership has reached nearly 10,000 with two large annual meetings and a thriving publications effort-Journal of Materials Research, the MRS Bulletin, and numerous proceedings volumes. Joumal of Materials Research recently appointed associate editors, W. Lutze (Europe) and Shigeyuki Sōmiya (Japan), to expedite the handling of manuscripts abroad. The MRS Bulletin, which also has an associate editor in Europe, I.W. Boyd, indicated its interest in expanding its coverage of materials research news from other areas of the world.

The European Materials Research Society (E-MRS) recently held elections to establish a new Board of Delegates, nearly one-third of which are new members. The E-MRS conducts two meetings a year, as well as workshops and summer schools. Recently, a principal accomplishment of EMRS was the establishment of networks of scientific collaboration whose interactions are supported by the European Economic Community.

In Japan, the Advanced Materials Sci- ence and Engineering Society (AMSES) held its inaugural meeting in March 1989 in Tokyo. Prof. Masao Doyama was elected president with Professors S. Sōmiya and M. Hasegawa as vice presidents. AMSES also sponsors two major meetings a year, held in July and December. Prof. Sōmiya will serve as the president in 1990.

MRS-India reported a membership of approximately 500. Its Council of Management is chaired by Prof. C.N.R. Rao as president. The first meeting of MRS-India will be held in February 1990.

The Chinese Society for Materials Science in Taiwan, China, has over 1,000 members and 48 participating organizations which join together in an annual meeting. Their annual growth rate in the number of papers presented at their meetings has been over $70 \%$ per year.

In Mexico, the Mexican Surface and Vacuum Society has been the representative body of the Mexican community involved in materials research. However, a new society is being organized in Mexico whose purpose is to cover more adequately all the

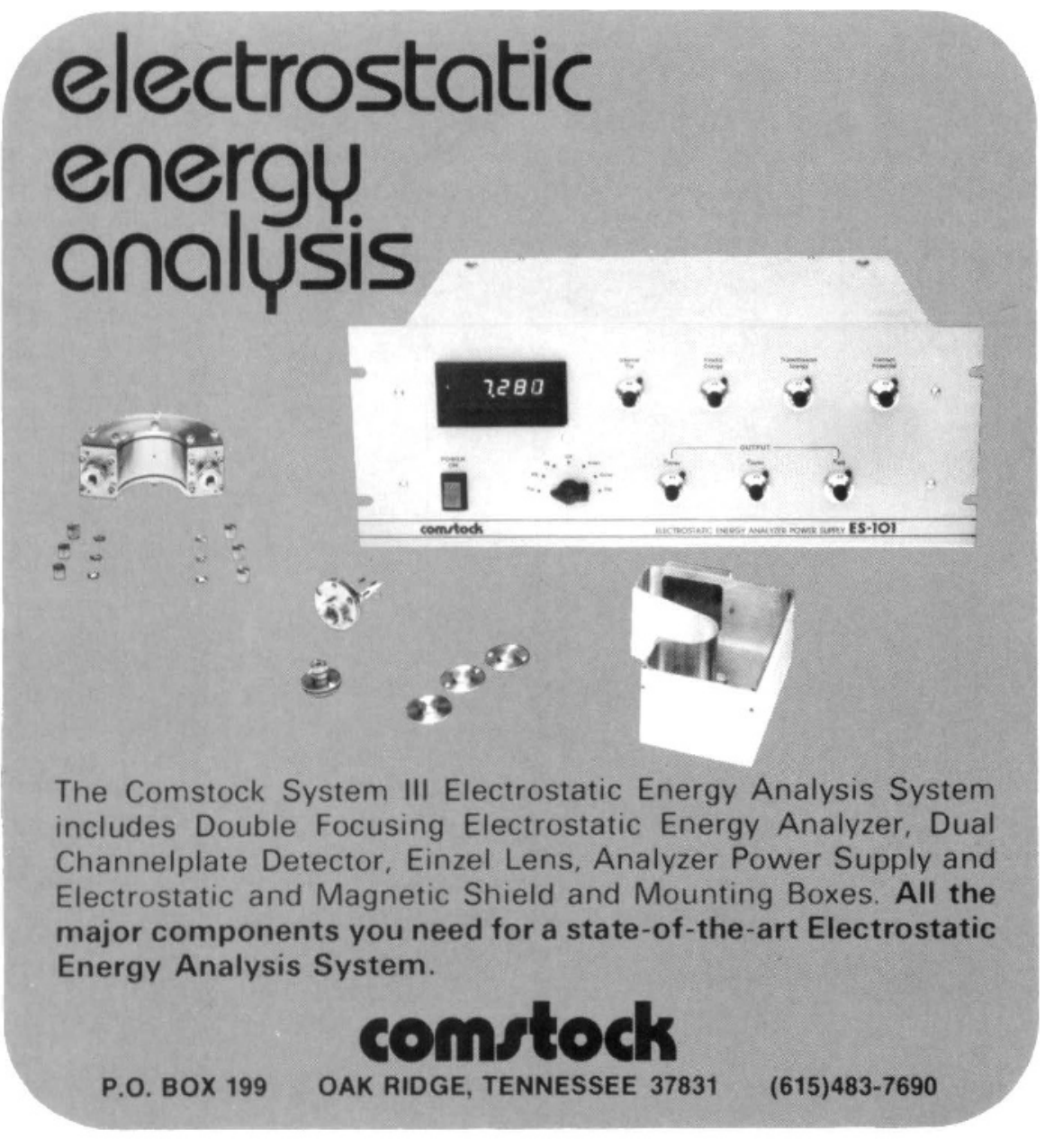

areas of interest to the growing materials research community. Tentative plans are for the new society to have its first national meeting in spring 1990 when officers will be elected. Preliminary contacts are being made with other Central and South American countries.

The Australian Materials Research Committee has been established as a first step in the creation of an Australian-MRS. The committee presently has delegates from the Australian Institute of Physics and the Institute of Metals and Materials of Australia. Delegates from other societies will be nominated over the next half year. The first joint meeting will be held in 1990.

In China, C-MRS held two meetings in 1989 and will hold an international meeting in Beijing, June 18-22, 1990, spanning 14 individual symposia covering topics such as high $T_{c}$ superconductors, optoelectronic materials, laser and particle-beam interactions with solids, intermetallic and high temperature materials, and biomedical materials. The abstract deadline for the meeting has been extended.

\section{Cooperative IMRC Activities Already Under Way}

In addition to the activities of individual Adhering Bodies, symposia are already being arranged with joint sponsorship by Adhering Bodies and other international groups. In September 1990, the Conference on Electronic Materials will be held in Newark, New Jersey, co-sponsored by the Japan Society of Applied Physics, the Materials Research Society, and the European Materials Research Society. E-MRS President G.G. Bentini suggested that in 1991 the International Advanced Materials Conference be held at the E-MRS Spring Meeting and that the International Conference on Electronic Materials be held at an EMRS meeting in 1992. Both of these meetings will be co-chaired by representatives from Europe, Asia and North America. In Fall 1991, MRS and E-MRS will co-sponsor the Fifteenth International Symposium on the Scientific Basis for Nuclear Waste Management in Strasbourg.

Bob Chang, 1989 president of MRS, closed the meeting by congratulating participants for taking the important step of creating the International Materials Research Committee-the first step toward an international union or federation. The meeting adjourned for a fine inaugural dinner.

Rodney C. Ewing University of New Mexico

*Editor's Note: For background on the activities of the Adhering Bodies and development of the IMRC, see the MRS Bulletin Vol. XIV No. 5 (May 1989) p. 46 and Vol. XIII No. 9 (September 1988) p. 29. 